\title{
An Engineering Analysis of the Aortic Valve Dynamics in Patients with Rotary Left Ventricular Assist Devices
}

\author{
George Faragallah and Marwan A. Simaan, PhD, PE \\ Department of Electrical Engineering and Computer Science, University of Central \\ Florida, Orlando, FL, USA
}

Submitted November 2012. Accepted for publication May 2013.

\begin{abstract}
The use of a rotary Left Ventricular Assist Device (LVAD) as a bridge-to-recovery treatment is gaining considerable attention in the LVAD research community. Using a mathematical model of the cardiovascular-LVAD system, this paper intends to define the critical control parameters in terms of power and rotational speed of the LVAD to ensure normal dynamics of the aortic valve for different levels of patient's activity and severity of heart failure. The effects of permanent closure of the aortic valve on the hemodynamics of the patient and the pump flow characteristics, if the critical control values are exceeded, are also examined. Additionally, LVAD power and speed control parameters that yield a given percentage of the cardiac cycle during which the aortic valve remains open are examined indicating that the severity of the heart failure is a very important factor in deciding the appropriateness of the LVAD as a bridge-to recovery treatment.
\end{abstract}

Keywords: aortic valve, left ventricular assist devices, bridge to recovery

\section{INTRODUCTION}

The American Heart Association (AHA) estimates that 5.8 million patients above the age of 20 in the United States currently suffer from heart failure, a condition in which the heart cannot pump enough blood into the circulatory system [1]. The Left Ventricular Assist Device (LVAD) is a rotary mechanical blood pump that can help heart failure patients by pumping blood from the left ventricle to the aorta. The rate of flow of the pumped blood is controlled by the rotational speed of the LVAD pump. When the speed is increased by properly adjusting the power delivered to the pump, the blood flow increases, providing more support to the body of the patient. The LVAD is typically implanted in heart failure patients for three different types of treatments [2-4]: (a) Bridge to Transplantation: This type of treatment is typically intended for patients awaiting a heart transplant. These patients can wait for long periods of time before a suitable donor heart is available. The LVAD can be implanted, in these cases,

*Corresponding Author: Marwan A. Simaan, Department of Electrical Engineering and Computer Science, University of Central Florida, 4000 Central Florida Blvd., Orlando, FL 32816. Phone: (407) 882-2220. E-mail: simaan@eecs.ucf.edu. Other author: georgef@knights.ucf.edu. 
temporarily to help the native heart until a donor heart becomes available and the heart transplantation is performed.

(b) Bridge to Recovery: This type of treatment is typically intended for patients whose heart condition may improve as a result of the LVAD support. It was observed [5-10] that some patients can be weaned from the LVAD as their hemodynamic and physiological changes indicate recovery of the heart muscle. As in the case of the bridge-to-transplant treatment, the LVAD support in this case is also temporary and is kept until recovery occurs. At that point, the device can be explanted and the patient goes back to leading a normal life.

(c) Destination Therapy: This type of treatment is typically intended for patients who are not suitable candidates for heart transplantation due to their age or condition and whose heart failure condition is permanent to the extent that recovery cannot occur. In such cases, the LVAD is intended to be implanted permanently in order to prolong survival and improve the patient's quality of life [2].

The LVAD considered in this paper is one that is purposed as a bridge-to-recovery device. This is a very critical use of the device that has received considerable attention in recent years but has not been fully understood, at least from an engineering perspective. We believe that the LVAD will need to be operated differently when its purpose is bridge-to-recovery as compared to the other two types of treatment. The focus of our study is to determine the proper range for operating the LVAD pump which can maintain normal aortic valve dynamics (i.e., the aortic valve opening once for an appropriate percent of the duration of the cardiac cycle) while at the same time providing adequate blood supply to the patient's circulatory system. This range is defined in terms of the power delivered to the LVAD, and consequently the rotational speed of the LVAD pump.

It is well understood that the permanent closure of the aortic valve during the LVAD support is an important factor that can delay or prevent the recovery of the heart [11, 12]. Permanent closure of this valve can happen when the power delivered to the LVAD pump motor, and consequently the pump speed, reach critical values beyond which any further increase in power and speed will lead to a permanent closure of the aortic valve. This occurs due to the inability of the ventricle to create enough volume that can build pressure high enough to open the aortic valve and let the blood flow through it. The resulting permanent closure of the aortic valve may cause numerous complications such as (1) significant adverse changes in the patient's hemodynamic conditions, (2) aortic valve fusion or stenosis which occurs to about $88 \%$ of LVAD patients [11], and (3) stagnation of blood flow and thrombus formation [13]. The latter may cause coronary occlusion, which means the oxygenated blood intended to feed the heart muscle will be blocked by the thrombus formed on the coronary. These complications have no major impact in cases when the LVAD is used as a bridge-to-transplant or as destination therapy treatments [11]; however, it is extremely important that they be avoided in bridge-to-recovery treatments. The normal operation (i.e., opening and closing) of the aortic valve will help prevent these complications by keeping the heart muscle active in doing a part of the pumping function. Also, flow through the aortic valve will help washout the thrombus formed around the valve, and blood will flow through the 
coronary to feed the heart muscle. On the other hand it should be noted that recent studies have concluded that thrombotic events were more likely in patients with more frequent aortic valve openings, who were maintained on lower LVAD speeds [14]. This raises the concern that reduced flow through the pump might predispose patients to thrombotic events.

The critical power delivered to the pump motor, which causes the motor speed to close the aortic valve, is not fixed. In fact, it varies largely as a function of the severity of the heart failure condition as well as the level of activity of the patient. Thus, the objective of this paper is to investigate the relationship between the critical power delivered to the LVAD pump, and the corresponding critical speed at which permanent closure of the aortic valve occurs, and the levels of patient's heart failure and activity. The effects of permanent closure of the aortic valve on both the patient's hemodynamics and pump performance characteristics were also explored. In order to accomplish these objectives, we relied on the combined cardiovascular-LVAD mathematical model derived in our earlier works [15-18].

This paper is organized as follows: The $6^{\text {th }}$ order state-space model of the combined cardiovascular-LVAD system used throughout the analysis and the method applied to detect the permanent closure of the aortic valve are reviewed in Section 2. Results of the study and the effect of the LVAD power on the aortic valve dynamics are presented in Section 3. A discussion of the results is included in Section 4, and concluding remarks are presented in Section 5.

\section{METHODS}

The mathematical model used in this paper for the combined cardiovascular-LVAD system was previously introduced and validated in $[15,16]$. The model assumes the patient to have a healthy pulmonary circulation and right ventricle to the extent that their effect on the LVAD can be ignored. The left ventricle and the systemic circulation are modeled as a $5^{\text {th }}$ order autonomous nonlinear time-varying dynamical system. The LVAD considered in our earlier works [15-18] as well as this paper is a rotary pump which can be modeled as a $1^{\text {st }}$ order dynamical system. The resulting combined biomechanical system is therefore a $6^{\text {th }}$ order system that is used to represent a heart failure patient implanted with an LVAD system.

\subsection{The Combined Cardiovascular-LVAD Model}

An electric circuit equivalent model of this system is shown in Figure 1. The differential equations that govern the behavior of this system are summarized in the appendix and additional details on the model can be found in [15-18]. In the following subsections, we will elaborate further on three parameters in the model since extensive reference is made to them in this paper.

(a) The Aortic Valve: The aortic valve is represented in Figure 1 by the non-ideal diode consisting of a resistance $R_{A}$ and ideal diode $D_{A}$. The aortic compliance is represented by the capacitor $C_{A}$. A diode is either a short-circuit or an open-circuit depending on the flow of current through its terminals. In this sense, the diode $D_{A}$ can perfectly represent the aortic valve because the valve opens when the blood flows from the ventricle to the 


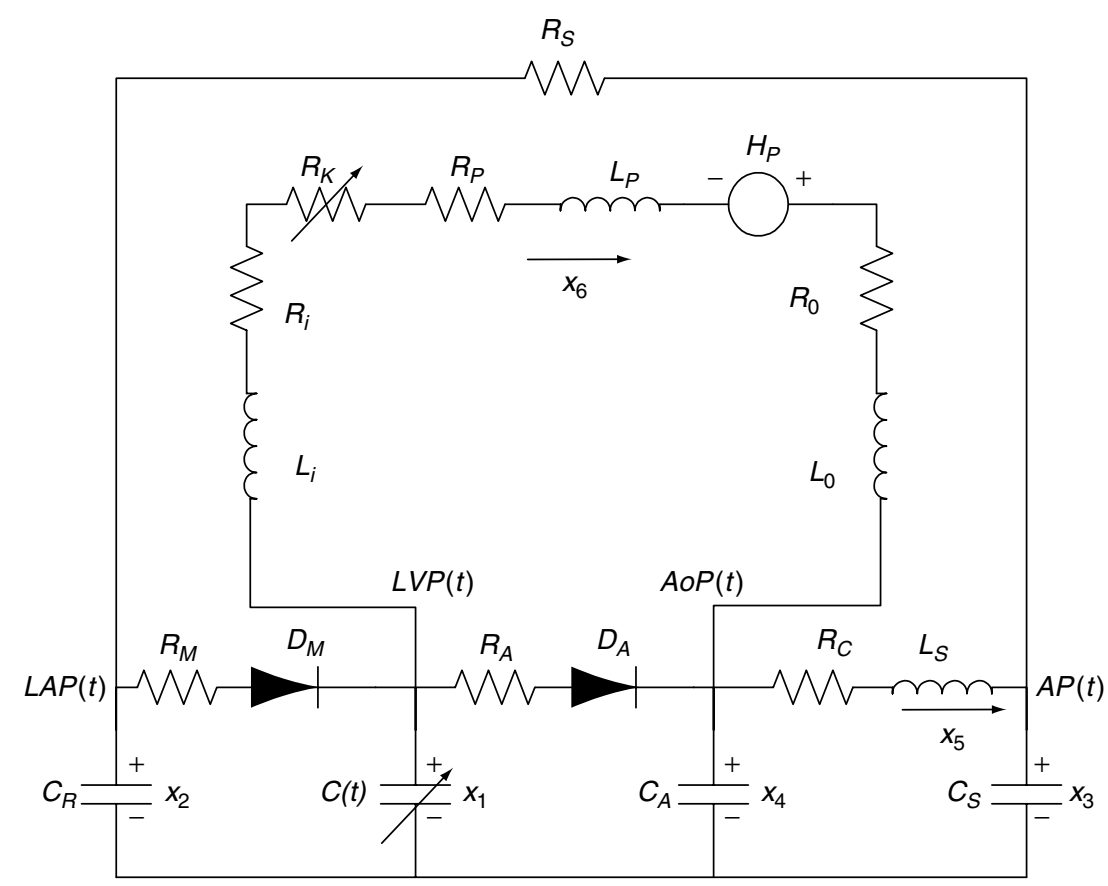

Figure 1. The combined cardiovascular-LVAD circuit model.

aorta and closes when the flow direction is reversed. Clearly, permanent closure of the aortic valve essentially corresponds to diode $D_{A}$ in our model being permanently opencircuited.

(b) The Systemic Vascular Resistance: The Systemic Vascular Resistance, represented in Figure 1 by $R_{S}$, is the total resistance of the systemic circulation to the blood flow. When it increases, arterial pressure also increases which, in turn, reduces the cardiac output [19]. The overall diameter of the blood vessels in the systemic circulation is the most important factor that affects this resistance [20]. As a result of a complex physiological process, the systemic vascular resistance decreases during exercise allowing more blood flow into the circulation, but it increases during rest. The value for $R_{S}$ in our model can be varied to simulate different level of activities of the patient. Small values of $R_{S}$ are used to simulate high levels of activity (such as fast walking or running, for example), while high values of $R_{S}$ are used to simulate low levels of activity (such as rest or sleeping). In our model, we use a value of $R_{S}=1.0 \mathrm{mmHg} \cdot \mathrm{s} / \mathrm{ml}$ to represent a moderate level of activity.

(c) The Ventricular Elastance: The ventricular elastance $E(t)$, represented by the inverse of the capacitance $C(t)$ in Figure 1, represents the relationship between the left ventricle pressure $\operatorname{LVP}(t)$ and the left ventricle volume $\operatorname{LVV}(t)$ [21, 22]. This relationship is described mathematically by the expression: 


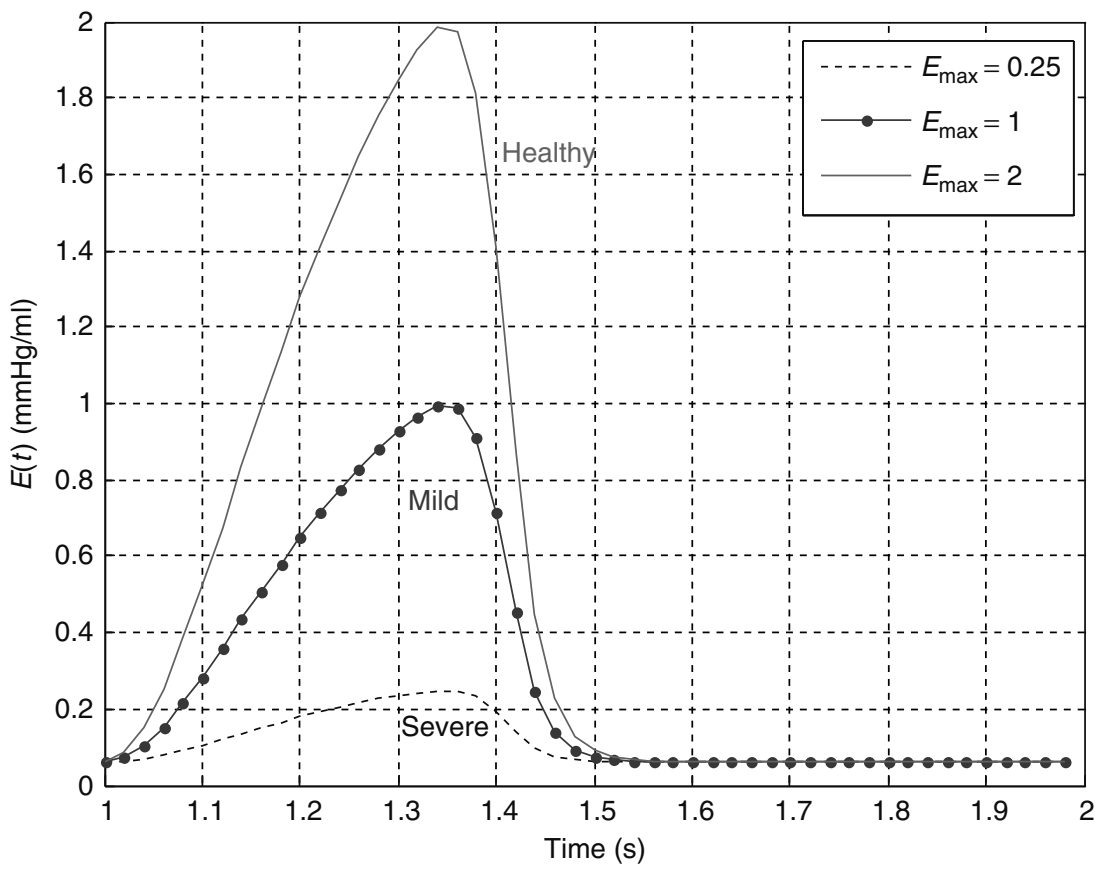

Figure 2. Ventricular Elastance $E(t)$ for different levels of heart condition.

$$
E(t)=\frac{L V P(t)}{L V V(t)-V_{0}}
$$

where $V_{0}$ is a reference volume. Figure 2 shows plots of $E(t)$ for three different heart conditions: a healthy left ventricle, a left ventricle with mild heart failure, and a left ventricle with severe heart failure. The maximum value $E_{\max }$ of the elastance function $E(t)$ can be used as a parameter indicator of the heart condition. In our model, a value $E_{\max }=2 \mathrm{mmHg} / \mathrm{ml}$ is used to represent a healthy heart and values of $E_{\max }$ less than 2 are used to represent different levels of heart failure as illustrated in Figure 2.

\subsection{The Pump Motor Power}

The LVAD pump considered in this paper is a rotary blood pump that is driven by a DC motor. In Figure 1, the LVAD pump is represented by the branch within the circuit that starts at $L V P(t)$ and ends at $A o P(t)$. The pressure head (gain) across the pump is modeled as a voltage source $H_{p}$ with an internal resistance and inductance combination $\left\{R_{p}, L_{p}\right\}$. The pump is connected to the left ventricle via an inlet cannula modeled as $\left\{R_{i}, L_{i}\right\}$ and to the aorta via an outlet cannula modeled as $\left\{R_{0}, L_{0}\right\}$. A nonlinear resistance $R_{K}$ is included in the circuit to model the effect of ventricular suction when it occurs $[15,16]$. 
The rotation of the impeller of the pump causes a large pressure difference that forces the blood to flow from the inlet cannula through the pump to the outlet cannula. The rotational speed $\omega$ of the impeller is a function of the electric power $P_{E}$ delivered to the motor of the pump. Since $\omega$ is the main variable that affects the dynamics of the aortic valve and can cause it to close permanently, it is therefore importants to examine the relationship between $\omega$ and the electric power $P_{E}$ delivered to the pump, which acts as the control variable in our model.

From Figure 1, the pressure difference between the left ventricle and the aorta is characterized by the following differential equation:

$$
L V P(t)-A o P(t)=R^{*} Q_{p}(t)+L^{*} \frac{d Q_{p}(t)}{d t}-H_{p}
$$

where $H_{p}$ is related to $\omega$ according to [14]:

$$
H_{p}=\beta \omega^{2}(t)
$$

and $\beta=9.9025 \times 10^{-7} \mathrm{mmHg} /(\mathrm{rpm})^{2}$. In equation $(2), Q_{P}(t)$ is the pump flow, and $R^{*}$ and $L^{*}$ are the total resistance and inductance in the LVAD portion of the circuit; i.e.,

$$
\begin{gathered}
R^{*}=R_{i}+R_{0}+R_{p}+R_{K} \\
L^{*}=L_{i}+L_{0}+L_{p}
\end{gathered}
$$

The direct relation between $P_{E}$, the electrical power delivered to the motor, and $P_{P}$, the hydrodynamic power generated by the pump that can be used to determine the pressure head $H_{p}$ in (2) is as follows:

$$
P_{P}=\eta P_{E}
$$

where $\eta$ is the electric to hydrodynamic power transfer efficiency. The hydrodynamic power $P_{p}$ can be written as the product of the density of the reference fluid $\rho$, acceleration of gravity $g$, pump head $H_{p}$, and the flow rate $Q_{p}(t)$ through the pump [23]. Therefore, equation (6) can be written as:

$$
\rho g H_{p} Q_{P}(t)=\eta P_{E}
$$

Solving for $H_{p}$ yields:

$$
H_{p}=\delta \frac{P_{E}}{Q_{P}(t)}
$$


where $\delta=\frac{\eta}{\rho g}$. For the LVAD used in our model, assuming that all energy losses are accounted for by the pressure losses induced by $R_{p}$ and $L_{p}$, we assume that $\eta=100 \%$. After applying the appropriate conversion factors, the constant $\delta$ can be computed to be $7495 \mathrm{mmHg} \cdot \mathrm{ml} / \mathrm{s} \cdot W$. Substituting eqn. (8) in eqn. (2) yields:

$$
L V P(t)-A o P(t)=R^{*} Q_{P}(t)+L^{*} \frac{d Q_{p}(t)}{d t}-\delta \frac{P_{E}}{Q_{P}(t)}
$$

Note that $P_{E}$ is the only control variable in the entire model. It can be changed by either manipulating the current $I$ or the voltage $V$ across the DC motor of the pump according to the relationship $P_{E}=V I$. It should also be noted that a relationship between $P_{E}$ and $\omega$, the rotational speed of the pump, follows directly from (3) as:

$$
\omega(t)=\sqrt{\frac{\delta P_{E}}{\beta Q_{P}(t)}}
$$

This relationship is highly nonlinear, and because of the dependence on $Q_{P}(t)$, a constant value of power applied to the LVAD motor will not lead to a constant rotational speed on the pump. Instead, the rotational speed of the pump will be periodic in nature as determined by eqn. (10) since $Q_{P}(t)$ is periodic. This phenomenon was studied in detail in [17] and [18]. For this reason, for the remainder of this paper when we refer to a rotational speed that corresponds to a value of $P_{E}$, we actually mean the average value of $\omega(t)$ over its period. Table 1 lists the six state variables in the model and Table 2 lists all the parameters, their physiological meaning and standard values for a typical patient [15].

\subsection{Detection of the Aortic Valve Closure}

As mentioned earlier, the main objective of this paper is to study the effect of the aortic valve dynamics on the hemodynamics of the LVAD patient and on the pump performance characteristics. To accomplish this, we excited our model with different

Table 1. State variables in the cardiovascular-LVAD Model

\begin{tabular}{lll}
\hline Circuit variable & Physiological variable & \multicolumn{1}{c}{$\begin{array}{c}\text { Physiological definition } \\
\text { (units) }\end{array}$} \\
\hline$x_{1}(t)$ & $L V P(t)$ & Left Ventricular Pressure $(\mathrm{mmHg})$ \\
$x_{2}(t)$ & $L A P(t)$ & Left Atrial Pressure $(\mathrm{mmHg})$ \\
$x_{3}(t)$ & $A P(t)$ & Arterial Pressure $(\mathrm{mmHg})$ \\
$x_{4}(t)$ & $A \circ P(t)$ & Aortic Pressure $(\mathrm{mmHg})$ \\
$x_{5}(t)$ & $Q_{T}(t)$ & Total Flow Rate $(\mathrm{ml} / \mathrm{s})$ \\
$x_{6}(t)$ & $Q_{P}(t)$ & Pump Flow Rate $(\mathrm{ml} / \mathrm{s})$
\end{tabular}


Table 2. Model parameters

\begin{tabular}{lcl}
\hline Circuit parameters & Value & \multicolumn{1}{c}{ Physiological definition } \\
\hline Resistances $(\mathrm{mmHg} \cdot \mathrm{s} / \mathrm{ml})$ & & \\
$R_{S}$ & 1.0000 & Systemic Vascular Resistance \\
$R_{M}$ & 0.0050 & Mitral Valve Resistance \\
$R_{A}$ & 0.0010 & Aortic Valve Resistance \\
$R_{C}$ & 0.0398 & Characteristic Resistance \\
$R_{i}, R_{0}$ & 0.0677 & Inlet and Outlet Pump Resistance \\
$R_{P}$ & 0.17070 & Pump Resistance \\
$R_{K}$ & See $[15]$ & Suction Resistance \\
Compliances $(\mathrm{ml} / \mathrm{mmHg})$ & & \\
$C(t)$ & Time-varying & Left Ventricle Compliance \\
$C_{R}$ & 4.4000 & Left Atrial Compliance \\
$C_{S}$ & 1.3300 & Systemic Compliance \\
$C_{A}$ & 0.0800 & Aortic Compliance \\
Inertances $\left(\mathrm{mmHg} \cdot \mathrm{s}^{2} / \mathrm{ml}\right)$ & & \\
$L_{S}$ & 0.0005 & Inertance of Blood in Aorta \\
$L_{i}, L_{0}$ & 0.0127 & Inlet and Outlet Inertance \\
$\mathrm{L}_{P}$ & 0.02177 & Pump Inertance \\
Valves (no units) & & \\
$D_{M}$ & - & Mitral Valve \\
$D_{A}$ & - & Aortic Valve
\end{tabular}

values of the control variable $P_{E}$ so that the effect of the pump on the aortic valve can be observed over a wide range of pump operation. It is imperative that this range includes the critical value of $P_{E}$, henceforth denoted by $P_{E}^{c}$ at which the permanent closure of the aortic valve first occurs.

There are two ways to detect the permanent closure of the aortic valve. In the circuit model of Figure 1, an aortic valve that is operating normally is represented by the diode $D_{A}$ remaining open (i.e., short circuit) during the ejection portion of each cardiac cycle. Permanent closure of the valve happens when $D_{A}$ closes (i.e., becomes open circuit) and remains closed for the entire duration of the cardiac cycle. Another way to detect the permanent closure of the aortic valve is to observe the blood flow to the aorta. This flow corresponds to the sum of the flow through the aortic valve and the flow coming through the pump. Thus, the aortic valve is considered closed when the blood flow through the aorta is equal to the blood flow coming through the pump; i.e., when $x_{5}(t)=x_{6}(t)$ in the circuit of Figure 1, for all $t$ during the cardiac cycle.

The permanent closure of the aortic valve depends mainly on two physiological factors: (i) the severity of the heart failure, and (ii) the activity level of the patient. To cover a wide range of these factors, we simulated nine different cases corresponding to combinations of three different levels of heart failure (represented by three different values of $E_{\max }$ ) and three different levels of patient activity (represented by three 
Table 3. Nine different cases representing combinations of three levels of heart failure and three levels of patient activity

\begin{tabular}{|c|c|c|c|c|}
\hline & \multicolumn{3}{|c|}{ Level of heart failure } \\
\hline & & $E_{\max }=1$ & $E_{\max }=0.75$ & $E_{\max }=0.5$ \\
\hline 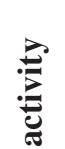 & $H R=120, R_{S}=0.5$ & $\begin{array}{l}\text { Mild heart failure. } \\
\text { Very active. }\end{array}$ & $\begin{array}{l}\text { Moderate heart } \\
\text { failure. } \\
\text { Very active. }\end{array}$ & $\begin{array}{l}\text { Severe heart } \\
\text { failure. } \\
\text { Very active. }\end{array}$ \\
\hline 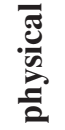 & $H R=75, R_{S}=1.0$ & $\begin{array}{l}\text { Mild heart failure. } \\
\text { Moderately active. }\end{array}$ & $\begin{array}{l}\text { Moderate heart } \\
\text { failure. } \\
\text { Moderately active. }\end{array}$ & $\begin{array}{l}\text { Severe heart } \\
\text { failure. } \\
\text { Moderately active. }\end{array}$ \\
\hline वे & $H R=60, R_{S}=1.2$ & $\begin{array}{l}\text { Mild heart failure. } \\
\text { Inactive. }\end{array}$ & $\begin{array}{l}\text { Moderate heart } \\
\text { failure. } \\
\text { Inactive. }\end{array}$ & $\begin{array}{l}\text { Severe heart } \\
\text { failure. } \\
\text { Inactive. }\end{array}$ \\
\hline
\end{tabular}

different values of $R_{\mathrm{s}}$ with corresponding values of heart rate, $H R$ ). These cases are summarized in Table 3.

\section{RESULTS}

The nine different cases defined in Table 3 have been simulated using our model for a range of $P_{E}$ from $0.12 \mathrm{~W}$ to $1.56 \mathrm{~W}$. Before summarizing the overall results, we will first describe in detail the results that correspond to only one representative case: a patient with mild heart failure and with a moderate level of activity (i.e., $E_{\max }=1, H R=75$ and $R_{S}=1.0$ ). We will then illustrate graphically the general results encompassing all nine cases to show the effects of the aortic valve dynamics for different levels of the severity of the heart failure as well as the activity level of the patient, as defined in Table 3.

Figure 3 shows a plot of the minimum, maximum (i.e., peak) and mean values of the blood flow rate through the aortic valve as a function of $P_{E}$. It is clear from this plot that the aortic valve closure occurs at the critical value of $P_{E}^{c}=0.84 W$ which corresponds to a critical speed of $\omega^{c}=9206 \mathrm{rpm}$. Note that the minimum values of the blood flow rate through the aortic valve are small negative values when pump power is below $P_{E}^{c}$. This small reverse flow in the aortic valve is due to the effect of the aortic compliance (denoted by $C_{A}$ in Figure 1). Physiologically, this is due to the adverse pressure gradient that is developed as the aortic flow begins to decelerate rapidly after reaching its peak which affects the low momentum fluid near the wall of the aorta, causing reverse flow in the sinus region [24]. Figure 3 also shows that as $P_{E}$ is increased starting at $0.12 \mathrm{~W}$, the mean value of blood flow rate through the aortic valve decreases, as expected, and the maximum value of the blood flow also decreases but at a much faster rate. This happens because as pump power is increased, the pump speed increases and resulting in a higher pressure difference between the left ventricle and aorta, which causes more blood to flow through the pump than through the aortic valve. This phenomenon is more 


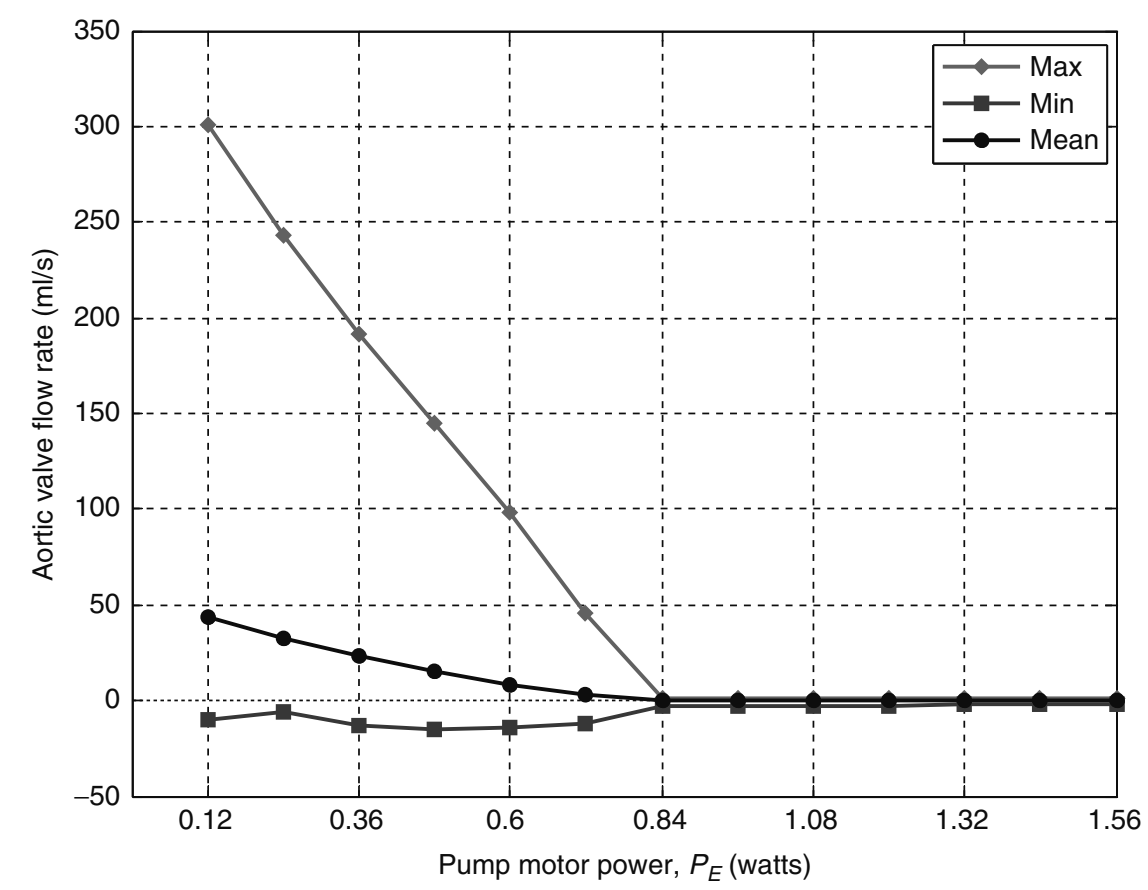

Figure 3. Change of aortic valve flow rate with pump motor power.

evident in Figure 4 which shows a plot of the pump flow rate as a function of $P_{E}$. While all values (max, mean and min) of the pump flow rate increase, as expected, as $P_{E}$ increases, the maximum value seems to exhibit a breakpoint at the critical power $P_{E}^{c}=0.84 \mathrm{~W}$ by remaining constant beyond $P_{E}^{c}$. This breakpoint in the slope of the maximum values of the pump flow occurs exactly when the aortic valve closes for the entire cardiac cycle and continues to be closed as $P_{E}$ is increased.

Figures 5 and 6 show plots of the left ventricular pressure and aortic pressure, respectively, as a function of $P_{E}$. It is interesting to note that after closure of the aortic valve at $P_{E}^{c}$, the aortic pressure increases sharply and the left ventricular pressure decreases moderately with its maximum value decreasing at a much faster rate. On the other hand, below $P_{E}^{c}$, the left ventricular pressure remains almost constant but the mean value of the aortic pressure increases while the maximum value remains almost constant. This latter observation is largely due to the fact that when the aortic valve operates normally, it remains open for a portion of the cardiac cycle which helps in keeping the maximum aortic pressure at a constant level.

An important factor that needs to be examined is the performance of the aortic valve prior to the time when it closes permanently. It is well known that for a healthy heart, a normal aortic valve remains open during about $30 \%$ of the cardiac cycle while blood is 


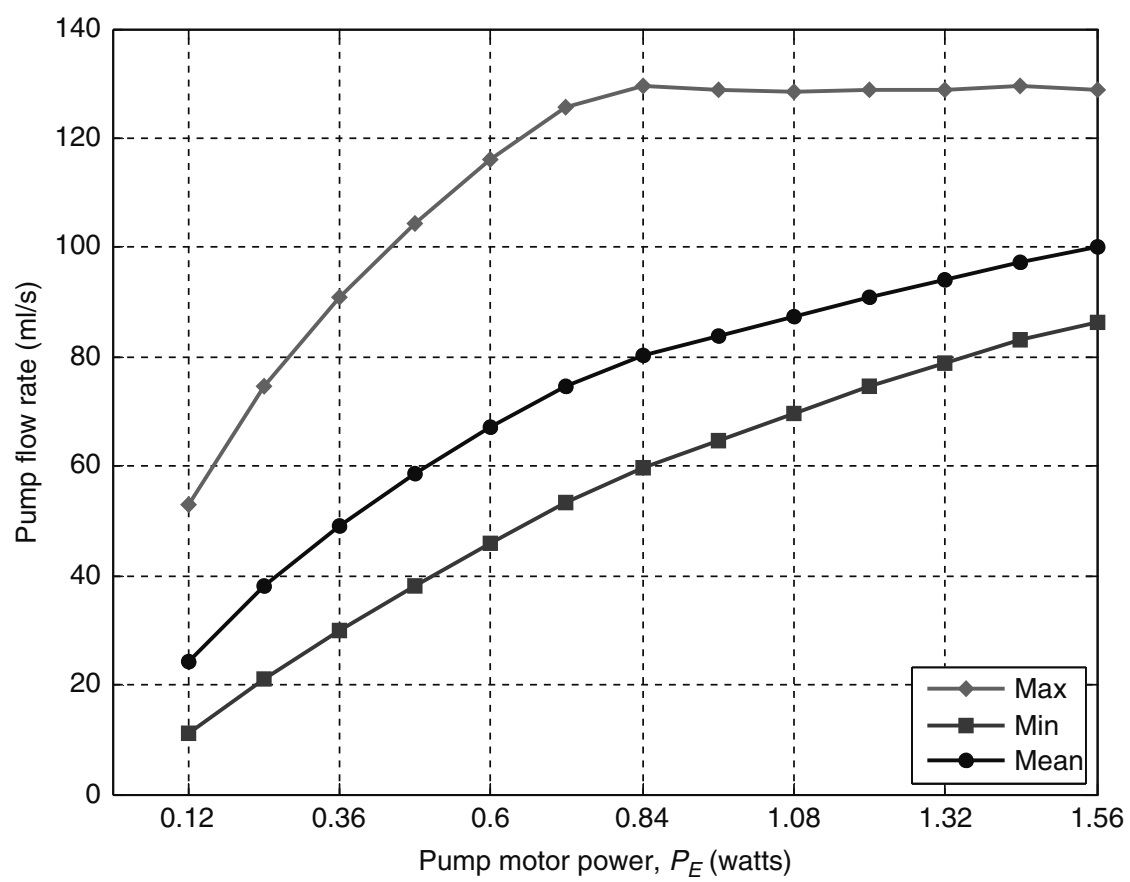

Figure 4. Pump flow rate as a function of pump motor power.

pumped through the valve to the aorta* [25]. In bridge-to-recovery LVAD treatment, clearly, the aortic valve does not instantaneously switch from normal operation (i.e., being open for a portion of the cardiac cycle) to complete closure. One would expect that as the power level increases, the duration when the aortic valve remains open during a cardiac cycle gradually decreases until permanent closure occurs at the critical values. This is actually confirmed in Figures 7,8 and 9 which show plots of the percentage of the cardiac cycle during which the aortic valve remains open for the mild, moderate and severe heart conditions, respectively, vs. the pump power. Each of these figures includes the three different cases of the activity level of the patient. It is interesting to note that, as expected, for an LVAD used as a bridge-to-recovery, the range of variation in the control variable is widest when the heart failure condition is mildest (as shown in Figure 7). In fact, for a very active patient with mild heart failure, the valve remains active - being open during about $13 \%$ of the cardiac cycle - even when $P_{E}$ reaches a value of $1.44 \mathrm{~W}$. On the other hand, for a patient with severe heart failure (as in Figure 9), it is extremely difficult to control the power delivered to the LVAD in such a way as to keep the aortic valve operating properly. The range of control

*This result is confirmed by our model which shows that the percentages of the valve opening during one cardiac cycle for a patient with No LVAD are $30.5 \%$ for a healthy heart, $27 \%$ for mild, $26 \%$ for moderate and $25 \%$ for severe heart failure. 


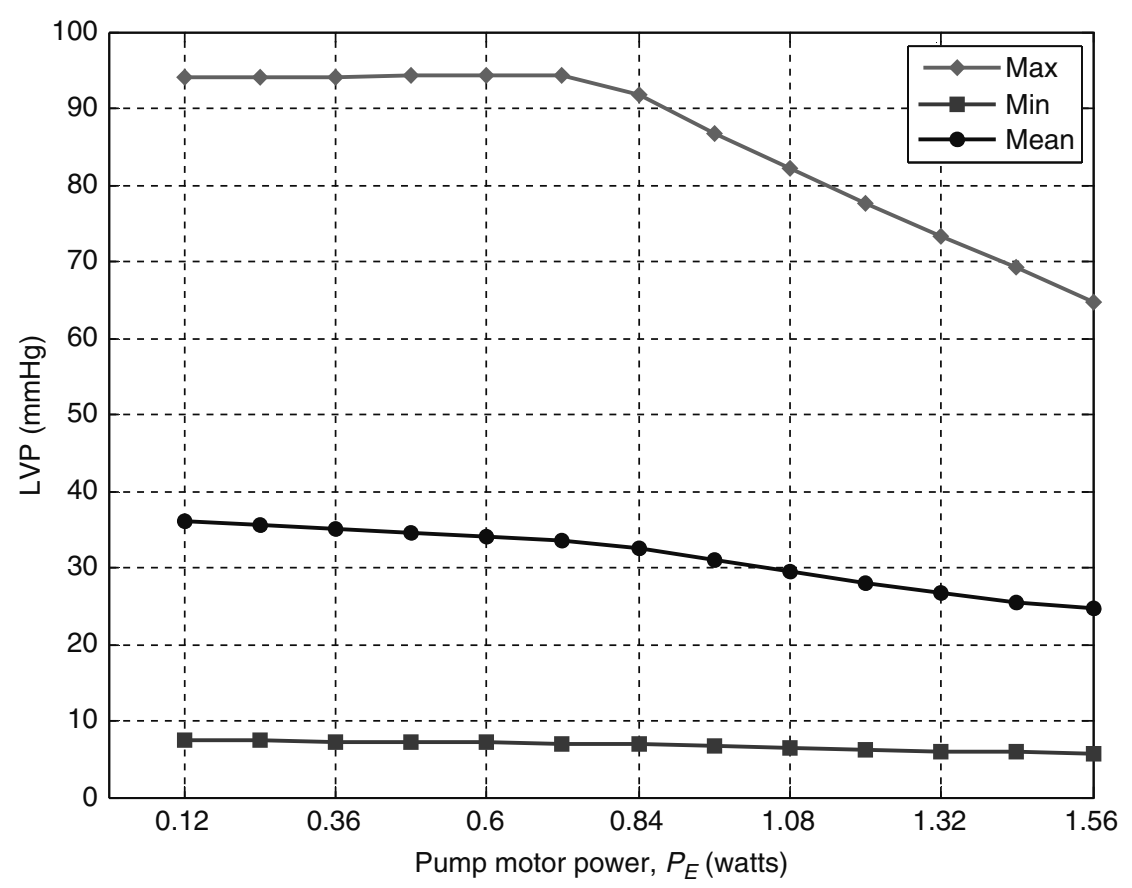

Figure 5. Left ventricle pressure as a function of pump motor power.

over which the valve remains operating properly is very narrow, lower than $0.36 \mathrm{~W}$ for moderately active and inactive patients and lower than $0.72 \mathrm{~W}$ for a very active patient. Comparing the three figures, it is important to note that regardless of the severity of heart failure, the more active the patient, the larger the $P_{E}^{c}$.

Since $P_{E}^{c}$ and $\omega^{c}$ are related by a complex nonlinear expression (eqn. 10), the values of $P_{E}^{c}$ and corresponding $\omega^{c}$ for the nine cases in Table 3 are given in Table 4.

The relationship between $P_{E}^{c}$ and $\omega^{c}$ shown in Table 4 is quite interesting but not surprising. First, increasing the power to the LVAD does not always necessarily mean increasing the speed. As is clear from eqn. 10, the speed is also dependent on the rate of blood flow through the pump, which may have a compensating effect on the speed (i.e., decreasing it even if $P_{E}$ is increasing). Second, for all three levels of activity, the weaker the heart, the lower the speed at which the aortic valve shuts down, as expected. For example, for an inactive patient, the aortic valve shuts down when the speed reaches $7798 \mathrm{rpm}$ if the heart is severely sick, but can hold off until the speed reaches $9244 \mathrm{rpm}$ if the heart is mildly sick. On the other hand, for a given level of heart failure, the lowest speed at which the aortic valve shuts down seems to vary with the level of activity. For a patient with mild or severe heart failure, the aortic valve shuts down first when the activity level is moderate at $9206 \mathrm{rpm}$ and $7453 \mathrm{rpm}$, respectively, but for a patient with moderate heart failure, the valve shuts down first at $8346 \mathrm{rpm}$ when the patient is 


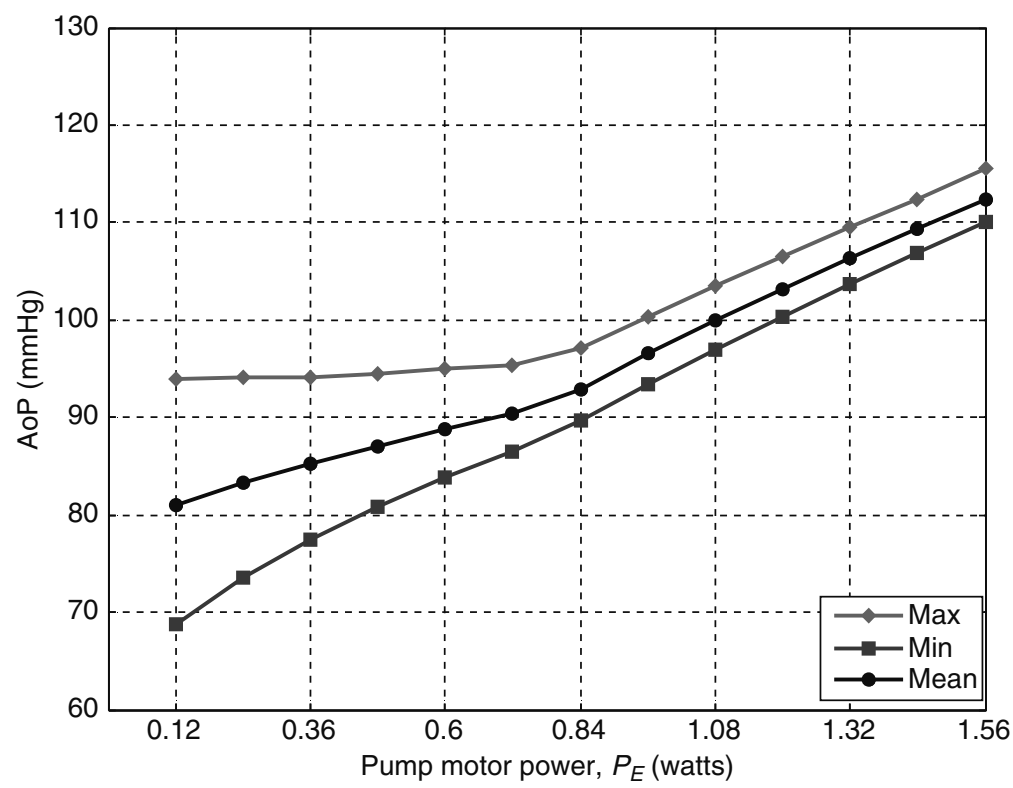

Figure 6. Aortic pressure as a function of pump motor power.

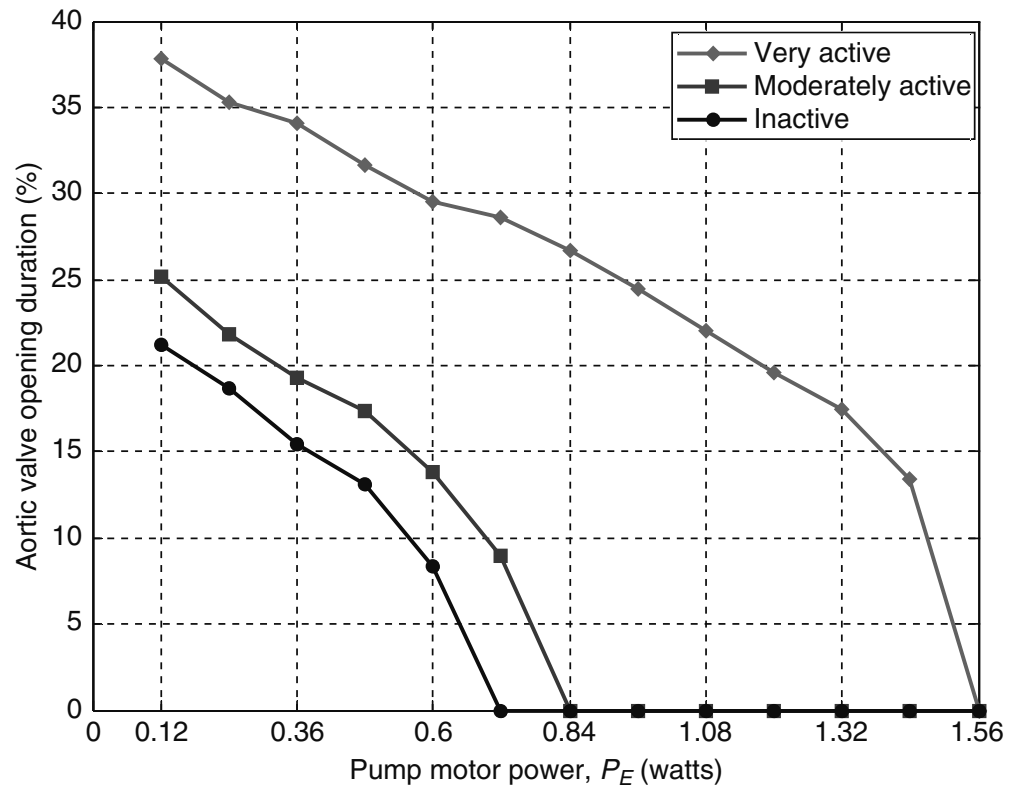

Figure 7. Aortic valve opening time as a percentage of the cardiac cycle for mild heart failure. 


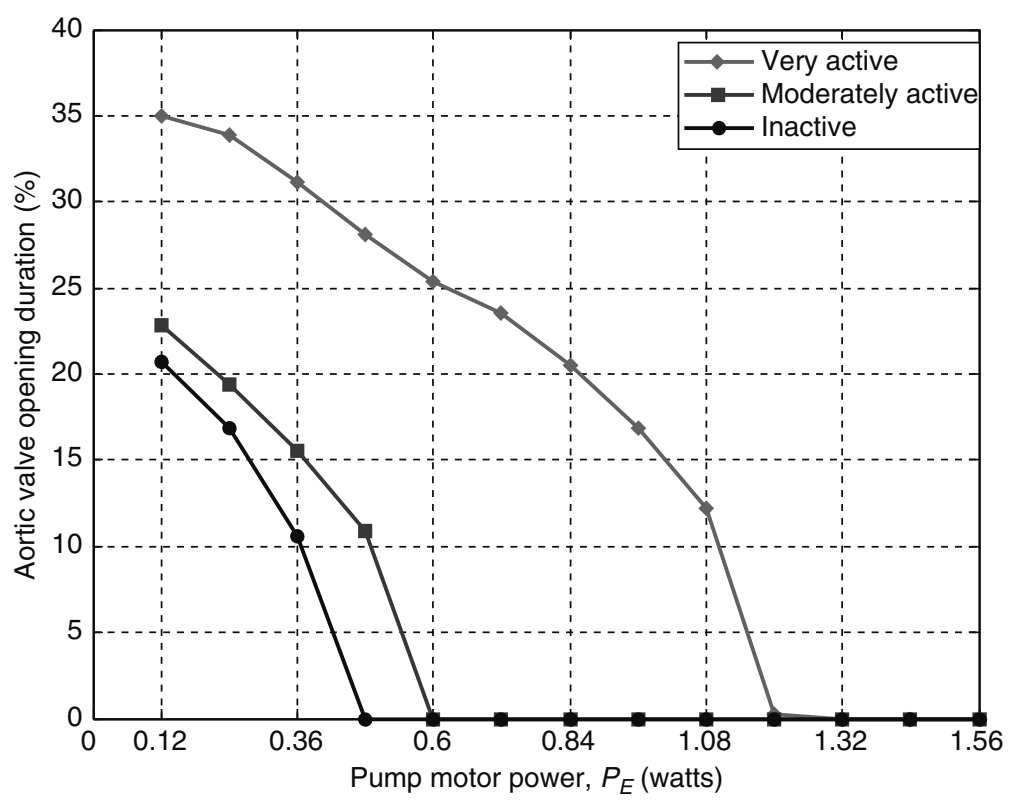

Figure 8. Aortic valve opening time as a percentage of the cardiac cycle for moderate heart failure.

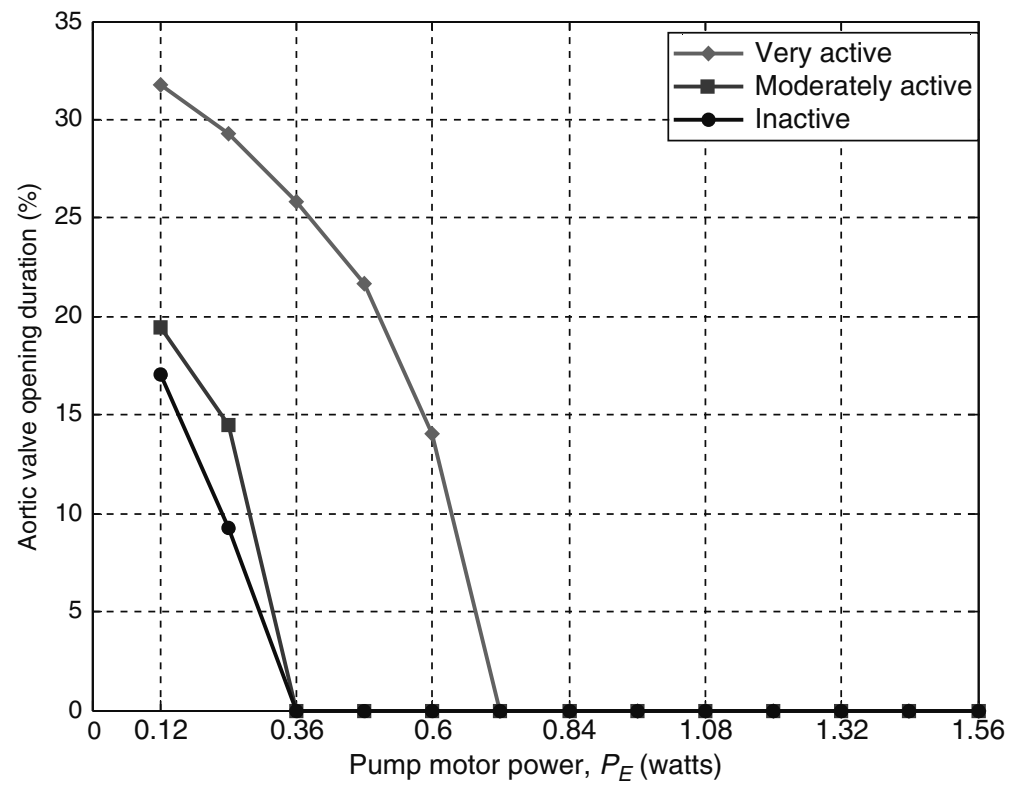

Figure 9. Aortic valve opening time as a percentage of the cardiac cycle for severe heart failure. 
Table 4. Critical pump power (in watts) and speed (in rpm) for the nine different cases (Table 3)

\begin{tabular}{lccc}
\hline & $\begin{array}{c}\text { Patient with } \\
\text { Mild Heart } \\
\text { Failure } \\
\boldsymbol{E}_{\mathbf{m a x}}=\mathbf{1 . 0 0}\end{array}$ & $\begin{array}{c}\text { Patient with } \\
\text { Moderate Heart } \\
\text { Failure } \\
\boldsymbol{E}_{\mathbf{m a x}}=\mathbf{0 . 7 5}\end{array}$ & $\begin{array}{c}\text { Patient with } \\
\text { Severe Heart } \\
\text { Failure }\end{array}$ \\
\hline Very Active Patient & $\boldsymbol{E}_{\mathbf{m a x}}^{c}=\mathbf{0 . 5 0}$ \\
$H R=120, R_{S}=0.5$ & $\omega^{c}=9407$ & $P_{E}^{c}=1.20$ & $P_{E}^{c}=0.72$ \\
Moderately Active Patient & $P_{E}^{c}=0.84$ & $P_{E}^{c}=0.60$ & $\omega^{c}=7778$ \\
$H R=75, R_{S}=1.0$ & $\omega^{c}=9206$ & $\omega^{c}=8460$ & $P_{E}^{c}=0.36$ \\
Inactive Patient & $P_{E}^{c}=0.72$ & $P_{E}^{c}=0.48$ & $\omega^{c}=7453$ \\
$H R=60, R_{S}=1.2$ & $\omega^{c}=9244$ & $\omega^{c}=8346$ & $P_{E}^{c}=0.36$ \\
& & & $\omega^{c}=7798$
\end{tabular}

inactive. What this essentially means is that for a given state of heart failure, if the level of activity of the patient is continuously changing, the pump should be operated at control values of power and speed that do not go above the lowest values that result in shutting down of the aortic valve. Finally, it is interesting to note that the results in Table 4 are minimally affected by the pump parameters in the model, suggesting that the above observations are valid for a wide range of LVADs whose pumps can be modeled as described in section 2.2 above. Our analysis indicates that the critical pump speeds remain within $\pm 0.7 \%$ of the nominal values shown in Table 4 when the pump parameters $R_{P}$ and $L_{P}$ are changed by $\pm 10 \%$ from their nominal values as shown in Table 2 .

Generally speaking, it would be preferable to operate the LVAD at control values that result in a specified percentage of the cardiac cycle for the aortic valve to remain open. As an illustrative example, Table 5 shows the pump power requirements and the resulting pump

Table 5. Pump power (in watts) and speed (in rpm) for the nine cases (in Table 3) to keep the aortic valve open during $15 \%$ of the duration of the corresponding cardiac cycle

\begin{tabular}{lccc}
\hline & $\begin{array}{c}\text { Patient with } \\
\text { Mild Heart } \\
\text { Failure } \\
\boldsymbol{E}_{\mathbf{m a x}}=\mathbf{1 . 0 0}\end{array}$ & $\begin{array}{c}\text { Patient with } \\
\text { Moderate Heart } \\
\text { Failure } \\
\boldsymbol{E}_{\mathbf{m a x}}=\mathbf{0 . 7 5}\end{array}$ & $\begin{array}{c}\text { Patient with } \\
\text { Severe Heart } \\
\text { Failure } \\
\boldsymbol{E}_{\mathbf{m a x}}=\mathbf{0 . 5 0}\end{array}$ \\
\hline Very Active Patient & $P_{E}=1.39$ & $P_{E}=1.01$ & $P_{E}=0.59$ \\
$H R=120, R_{S}=0.5$ & $\omega=9141$ & $\omega=8478$ & $\omega=7470$ \\
Moderately Active Patient & $P_{E}=0.56$ & $P_{E}=0.37$ & $P_{E}=0.23$ \\
$H R=75, R_{S}=1.0$ & $\omega=8473$ & $\omega=7738$ & $\omega=6917$ \\
Inactive Patient & $P_{E}=0.38$ & $P_{E}=0.28$ & $P_{E}=0.15$ \\
$H R=60, R_{S}=1.2$ & $\omega=8212$ & $\omega=7693$ & $\omega=6764$
\end{tabular}


speeds that yield conditions where the aortic valve remains open for $15 \%$ of the duration of the corresponding cardiac cycle. Clearly, all of these values are below the critical values given in Table 4 and may be used as a guidelines for controlling the LVAD pump.

\section{DISCUSSION}

Our results show that the slope of the maximum values (peaks) of the pump flow vs. the power delivered to the LVAD exhibits a significant change after the permanent closure of the aortic valve. This is a very important and interesting phenomenon because pump flow is the only one among the six state variables in the system that is easily accessible for measurement. This change can be used to identify the critical control variables $\left(P_{E}^{c}\right.$ and $\left.\omega^{c}\right)$ that define the operating range of the LVAD for the normal functioning of the aortic valve. The power delivered to the LVAD must therefore be safely away from the value corresponding to this significant change in the slope of the maximum values of pump flow. The sharp increase of the maximum values of the aortic pressure after permanent closure of the aortic valve can have serious detrimental effects on the valve itself, often causing its deformation and collapse. This is one of the main complications associated with the permanent closure of the aortic valve.

One aspect of the results of interest is the level of cardiac support provided to the circulatory system in a bridge-to-recovery LVAD treatment. Table 6 shows the total blood flow rate in the circulatory system when the LVAD is operated to keep the aortic valve open for $15 \%$ of the duration of the corresponding cardiac cycle (i.e., using the control values shown in Table 5). The total rate of blood that flows in the circulatory system of a healthy person (with $E_{\max }=2$ ) at the same three levels of activity defined in Table 3 are also shown in Table 6. This table also shows the percentages for each of the nine blood flow rates with respect to the corresponding blood flow rate of a healthy heart. Note that in the case of mild heart failure, the total blood flow rate supplied to the circulatory system

Table 6. Blood flow required for healthy patient and for the nine cases defined in Table 3 to keep the aortic valve open during $15 \%$ of the duration of the corresponding cardiac cycle

\begin{tabular}{|c|c|c|c|c|}
\hline & \multicolumn{4}{|c|}{$\begin{array}{c}\text { Total Blood Flow Rate in } 1 / \mathrm{min} \text { and } \% \text { of Blood Flow Rate } \\
\text { Relative to a Patient with No Heart Failure }\end{array}$} \\
\hline & $\begin{array}{c}\text { Patient with } \\
\text { No Heart } \\
\text { Failure } \\
E_{\max }=\mathbf{2 . 0 0}\end{array}$ & $\begin{array}{c}\text { Patient with } \\
\text { Mild Heart } \\
\text { Failure } \\
E_{\max }=1.00\end{array}$ & $\begin{array}{c}\text { Patient with } \\
\text { Moderate Heart } \\
\text { Failure } \\
\boldsymbol{E}_{\max }=\mathbf{0 . 7 5}\end{array}$ & $\begin{array}{c}\text { Patient with } \\
\text { Severe Heart } \\
\text { Failure } \\
E_{\max }=0.50\end{array}$ \\
\hline Very Active Patient & 9.30 & 8.22 & 7.04 & 5.39 \\
\hline$H R=120, R_{S}=0.5$ & $100 \%$ & $88 \%$ & $76 \%$ & $58 \%$ \\
\hline Moderately Active Patient & 4.90 & 4.46 & 3.77 & 2.88 \\
\hline$H R=75, R_{S}=1.0$ & $100 \%$ & $91 \%$ & $77 \%$ & $59 \%$ \\
\hline Inactive Patient & 4.30 & 3.74 & 3.18 & 2.40 \\
\hline$H R=60, R_{S}=1.2$ & $100 \%$ & $87 \%$ & $74 \%$ & $56 \%$ \\
\hline
\end{tabular}


ranges between $87 \%$ and $91 \%$ of the blood flow rate required by a healthy heart. For the moderate heart failure case, this range is between $74 \%$ and $77 \%$, and for the severe heart failure case, this range is between $56 \%$ and $59 \%$. It is interesting to note that in each of these three cases, the range is very narrow ( 3 to $4 \%$ ), indicating that the LVAD's ability to meet the patient's need for blood flow is not much affected by the level of patient's activity level. However, for each level of activity, the LVAD's ability to meet the patient's blood need is highly dependent on the patient's heart failure condition. These percentages cover a much wider range (30 to $32 \%$ ) depending on the patient's heart condition. It is also important to note that in the severe heart failure case, the LVAD is only able to provide a little more than one half (56\% to 59\%) of required blood flow to sustain the patient's needs, leading to the intuitive conclusion that the LVAD may not be appropriate as a bridge-to-recovery treatment for patients with severe heart failure.

Finally, as can be seen from the results in Figures 7-9 and Table 4, the activity level of the patient plays an important role in determining the critical pump power and pump speed at which the aortic valve fails proper operation. These results suggest that in bridge-to-recovery treatment, the more active the patient is, the more active the aortic valve is, and as a result, the faster the recovery is likely to be. Furthermore, it is clear that in all cases, in order to keep the aortic valve functioning as actively as possible, it is recommended that the pump be operated at the lowest possible power level that is needed to provide the patient with the necessary level of cardiac support. The examples shown in Table 6 suggest that if the goal is to have the aortic valve remain open for around $15 \%$ of the cardiac cycle and to ensure that the circulatory system receives no less than $74 \%$ of the blood requirement of a healthy heart, then this can only be accomplished for patients with moderate to mild heart failure.

This research has a few limitations that should be mentioned. The conclusions of this study are based only on simulation results obtained from a mathematical model of the cardiovascular-LVAD system. As mentioned earlier, this model assumes a patient with a healthy pulmonary circulation and a healthy right ventricle, which is the case in about half of the heart failure patients, thus limiting the results to cases of only left ventricle failure. The critical pump power and the corresponding speed that cause closure of the aortic valve as discussed in this paper may be lower than the power and speed recommended by the pump manufacturer. Based on our results, the likelihood of this event occurring is highest in patients with severe heart failure and lowest in patients with mild heart failure, as can be seen in Figure 7-9 and Tables 4 and 5. This limits the applicability of the critical values of pump power and speed as an LVAD control guide for bridge-to-recovery treatment only to patients with mild or moderate heart failure conditions, who indeed would be the most likely candidates for bridge-to-recovery treatment. The operation of the LVAD pump at speeds lower than what is recommended by the manufacturer has not been proven to be safe and may cause further complications for the patient.

\section{CONCLUSION}

For heart failure patients receiving LVAD as a bridge-to-recovery treatment, controlling the LVAD in order to ensure proper operation of the aortic valve is important in avoiding complications that can delay or prevent heart recovery. This paper presents a method for defining the upper limit of the operating range of the pump 
power, and consequently the pump rotational speed, so as to ensure proper operation of the aortic valve and to prevent it from closing permanently. Our results based on simulation studies only using a mathematical model of the cardiovascular-LVAD system show that this upper limit depends on the severity of heart failure and the activity level of the patient. The more severe the heart failure, the lower the limit; however, the more active the patient, the higher the limit. A method for determining this limit from observation of the pump flow rate is also discussed. An increase in the power provided to the LVAD pump results in an increase in the rate of blood flowing through the pump, and leading to three important events. The first is a saturation of the maximum, or peak value, of pump flow once the critical value of pump power is reached, indicating complete closure of the aortic valve. The second is a sharp increase in the aortic pressure which can continue to build if the critical power is exceeded and aortic valve closed, easily harming the valve and possibly preventing heart recovery. The third is a very slow decrease in left ventricular pressure as compared to the increase in the aortic pressure, the net effect of which leads to a gradual reduction in the aortic valve's opening time during a cardiac cycle. Once the left ventricular pressure becomes smaller than the aortic pressure at the critical values of power, the aortic valve will close for the entire cardiac cycle and will remain closed thereafter. This condition needs to be completely avoided in the operation of the LVAD as a bridge-to-recovery treatment.

\section{ACKNOWLEDGEMENTS}

The authors would like to thank Eduardo Divo and Yu Wang for their help in this work. This research was supported in part by grant ECCS-0852440 from the National Science Foundation.

\section{CONFLICT OF INTEREST}

The authors indicate no potential conflicts of interest.

\section{NOMENCLATURE}

$E(t) \quad$ Ventricular elastance, $\mathrm{mmHg} / \mathrm{ml}$

$g \quad$ Acceleration of gravity, $\mathrm{m} / \mathrm{s}^{2}$

$H_{P} \quad$ Pressure difference between left ventricle and aorta, $\mathrm{mmHg}$

$H R \quad$ Heart rate, bpm

$P_{E} \quad$ Electrical Power, $W$

$P_{P} \quad$ Hydrodynamic power, $W$

$P_{E}^{c} \quad$ Critical electric power, $W$

\section{Greek}

$\rho \quad$ Density of a reference fluid, $\mathrm{kg} / \mathrm{m}^{3}$

$\eta \quad$ Electric to hydrodynamic power transfer efficiency, unitless

$\omega \quad$ Pump rotational speed, rpm

$\omega^{c} \quad$ Critical pump rotational speed, rpm

Other symbols are defined in Tables 1 and 2. 


\section{REFERENCES}

[1] Lloyd-Jones D, Adams RJ, Brown TM, Carnethon M, Dai S, De Simone G, Ferguson TD, Ford E, Furie K, Gillespie C, Go A, Greenlund K, Haase N, Hailpern S, Ho PM, Howard V, Kissela B, Kittner S, Lackland D, Lisabeth L, Marelli A, McDermott MM, Meigs J, Mozaffarian D, Mussolino M, Nichol G, Roger VL, Rosamond W, Sacco R, Sorlie P, Stafford R, Thom T, Wasserthiel-Smoller S, Wong ND, Wylie-Rosett J, on behalf of the American Heart Association Statistics Committee and Stroke Statistics Subcommittee. Heart disease and stroke statistics-2010 update: a report from the American Heart Association, Circulation, 2010,121:e46-e215.

[2] Shah R, Kommu S, Bhuriya R, Arora R. Left Ventricular Assist Devices: Emerging Modality for Long Term cardiac Support, in: G. Reyes (ed). New Aspects of Left Ventricular Assist Devices, InTech Publishers, Rijeka, Croatia, 2011, ch. 4, pp. 67-82.

[3] Mulloy DP, Mahapatra S, Kern JA. Treatment of Ventricular Arrhythmias in Patients undergoing LVAD therapy, in: Jeffery Shuhaiber (ed). Ventricular Assist Devices, InTech Publishers, Rijeka, Croatia, 2011, ch. 8, pp. 137-158.

[4] Radovancevic B, Vrtovec B, Frazier OH. Left Ventricular Assist Devices: An Alternative to Medical Therapy for End-Stage Heart Failure. Curr Opin Cardiol. 2003, 18(3): 210-214.

[5] Westaby S, Katsumata T, Houel R, Evans R, Pigott D, Frazier OH, Jarvik R. Jarvik 2000 Heart: Potential for Bridge to Myocyte Recovery. Circulation, 1998, 98: 1568-1574.

[6] Kumpati GS, McCarthy PM, Hoercher KJ. Left Ventricular Assist Devices Bridge to Recovery: A Review of the Current Status. Ann Thorac Surg, 2011,71: 103-108.

[7] Navaratnarajah M, Ibrahim M, Yacoub M, Terracciano C. Myocardial Recovery Following Left Ventricular Assist Device Therapy, in: G. Reyes (ed). New Aspects of Left Ventricular Assist Devices, InTech Publishers, Rijeka, Croatia, 2011, ch. 5, pp. 83-104.

[8] Birks EJ, Tansley PD, Hardy J, George RS, Bowles CT, Burke M, Banner NR, Khaghani A, Yacoub MH. Left Ventricular Assist Device and Drug Therapy for the reversal of Heart Failure. N Engl J Med, 2006, 355(18): 1873-1884.

[9] Maybaum S, Kamalakannan G, Murthy S. Cardiac Recovery during Mechanical Assist Device Support. Thoracic and Cardiovascular Surgery, 2008, 20:234-246.

[10] Drakos SG, Terrovitis JV, Anastasiou-Nana MI, Nanas JN. Reverse Remodeling during Long-Term Mechanical Unloading of the Left Ventricle. J Mol Cell Cardiol, 2007, 43(3): 231-242.

[11] Carr CM, Jacobs J, Park SJ, Karon BL, Williamson EE, Araoz PA. CT of Ventricular Assist Device. RadioGraphics, 2010, 30: 429-444.

[12] Posuwattanakul P. The Biomechanical Evaluation of the Aortic Valve Leaflet Fusion in the LVADAssisted Heart. MSc Thesis, San Diego State University, 2011.

[13] Crestanello JA, Orsinelli DA, Firstenberg MS, Sai-Sudhakar C. Aortic Valve Thrombosis after Implantation of Temporary Left Ventricular Assist Device, Interact Cardio Vasc Thorac Surg, 2009, 8: 661-662.

[14] Saeed O, Patel J, Rivera A, Camach-Rivera M, Goldstein DJ, Maybaum S, Patel SR. Aortic Valve Opening Predicts Thrombotic Events during Continuous Flow Left Ventricular Assist Device (CFLVAD) Support, Circulation, 2012, 126:A11343

[15] Simaan MA, Ferreira A, Chen S, Antaki JF, Galati DG. A Dynamical State Space Representation and Performance Analysis of a Feedback-Controlled Rotary Left Ventricular Assist Devices, IEEE Transactions on Control System Technology, 2009, 17(1): 15-28.

[16] Simaan MA. Rotary heart assist devices, Handbook of Automation.S. Nof (ed), Springer Verlag, 2009, pp. 1409-1422.

[17] Faragallah G, Wang Y, Divo E, Simaan MA. A New Current-Based Control Model of the Combined Cardiovascular and Rotary Left Ventricular Assist Device, Proceedings of the American Control Conference, San Francisco, CA, 2011.

[18] Simaan MA, Faragallah G, Wang Y, Divo E. Left Ventricular Assist Devices: Engineering Design Considerations, in: G. Reyes (ed). New Aspects of Left Ventricular Assist Devices, InTech Publishers, Rijeka, Croatia, 2011, ch. 2, pp. 21-42. 
[19] Haddy FJ, Scott JB. Cardiovascular Pharmacology, Ann. Rev. Pharmacol., 1966, 6:49-76.

[20] Gyton AC, Hall JE. Textbook of Medical Physiology, $9^{\text {th }}$ ed., W.B. Saunders, Philadelphia, PA 1996.

[21] Oommen B, Karamanoglu M, Kovacs SJ. Modeling time varying elastance: The meaning of load independence, Cardiovascular Engineering: An Intr. J., 2003, 3:123-130.

[22] Suga H, Sagawa K. Instantaneous pressure-volume relationships and their ratio in the excised, support canine left ventricle, Circulatory Res., 1974, 35(1):117-126.

[23] Wagner H-J, Mathur J, Introduction to Hydro Energy Systems: Basics, Technology and Operation, Springer, Berlin, 2011.

[24] Yoganathan AP, Lemmon JD, Ellis JT. Heart Valve Dynamics, in: Joseph D. Bronzino (ed) The Biomedical Engineering Handbook: Second Edition, CRC Press LLC, Boca Raton, FL, 2000, Ch. 29.

[25] Tuzun E, Rutten M, Dat M, Vosse F, Kadipasaoglu C, Mol B. Continues-Flow Cardiac Assistance: Effects on Aortic Valve Function in Mock Loop, Journal of Surgical Research, 2011, 171(2):443-447.

\section{APPENDIX - State Space Equations for the LVAD-Cardiovascular Model}

The differential equations in state space form governing the behavior of the combined cardiovascular-LVAD system shown in Figure 1 are the following:

$$
\left[\begin{array}{c}
\dot{x}_{1} \\
\dot{x}_{2} \\
\dot{x}_{3} \\
\dot{x}_{4} \\
\dot{x}_{5} \\
\dot{x}_{6}
\end{array}\right]=\left[\begin{array}{cccccc}
\frac{-\dot{C}(t)}{C(t)} & 0 & 0 & 0 & 0 & \frac{-1}{C(t)} \\
0 & \frac{-1}{R_{S} C_{R}} & \frac{1}{R_{S} C_{R}} & 0 & 0 & 0 \\
0 & \frac{1}{R_{S} C_{S}} & \frac{-1}{R_{S} C_{S}} & 0 & \frac{1}{C_{S}} & 0 \\
0 & 0 & 0 & 0 & \frac{-1}{C_{A}} & \frac{1}{C_{A}} \\
0 & 0 & \frac{-1}{L_{S}} & \frac{1}{L_{S}} & \frac{-R_{C}}{L_{S}} & 0 \\
\frac{1}{L^{*}} & 0 & \frac{-1}{L^{*}} & \frac{-R^{*}}{L^{*}}
\end{array}\right]+\left[\begin{array}{c}
x_{1} \\
x_{2} \\
x_{3} \\
x_{4} \\
x_{5} \\
x_{6}
\end{array}\right]+
$$


A listing of the six state variables and various parameters in the above equations are shown in Tables I and II respectively. In the above expression, $\dot{C}(t)=\frac{d C(t)}{d t}$ and $r(x)$ represents the ramp function defined as follows:

$$
r(\xi)=\left\{\begin{array}{ccc}
\xi & \text { if } & \xi \geq 0 \\
0 & \text { if } & \xi<0
\end{array}\right.
$$





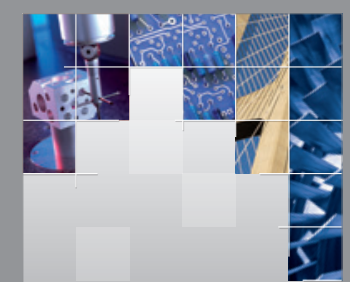

\section{Enfincering}
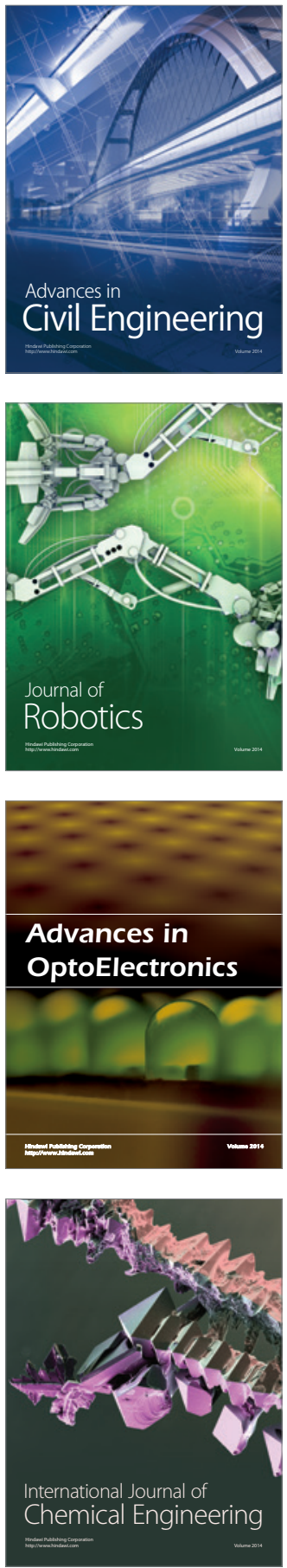

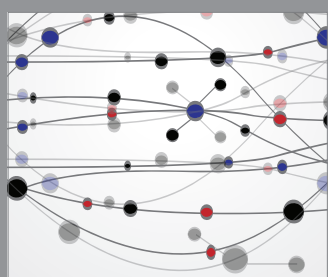

The Scientific World Journal

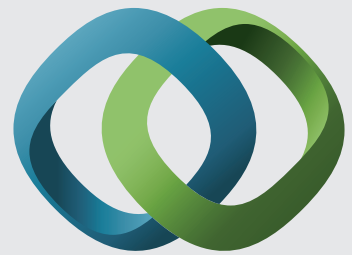

\section{Hindawi}

Submit your manuscripts at

http://www.hindawi.com
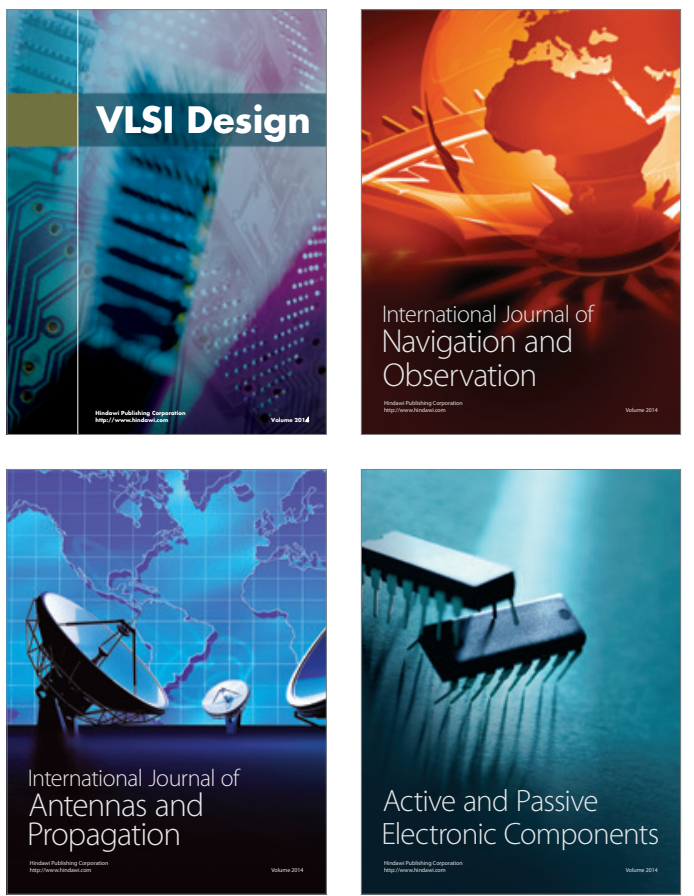
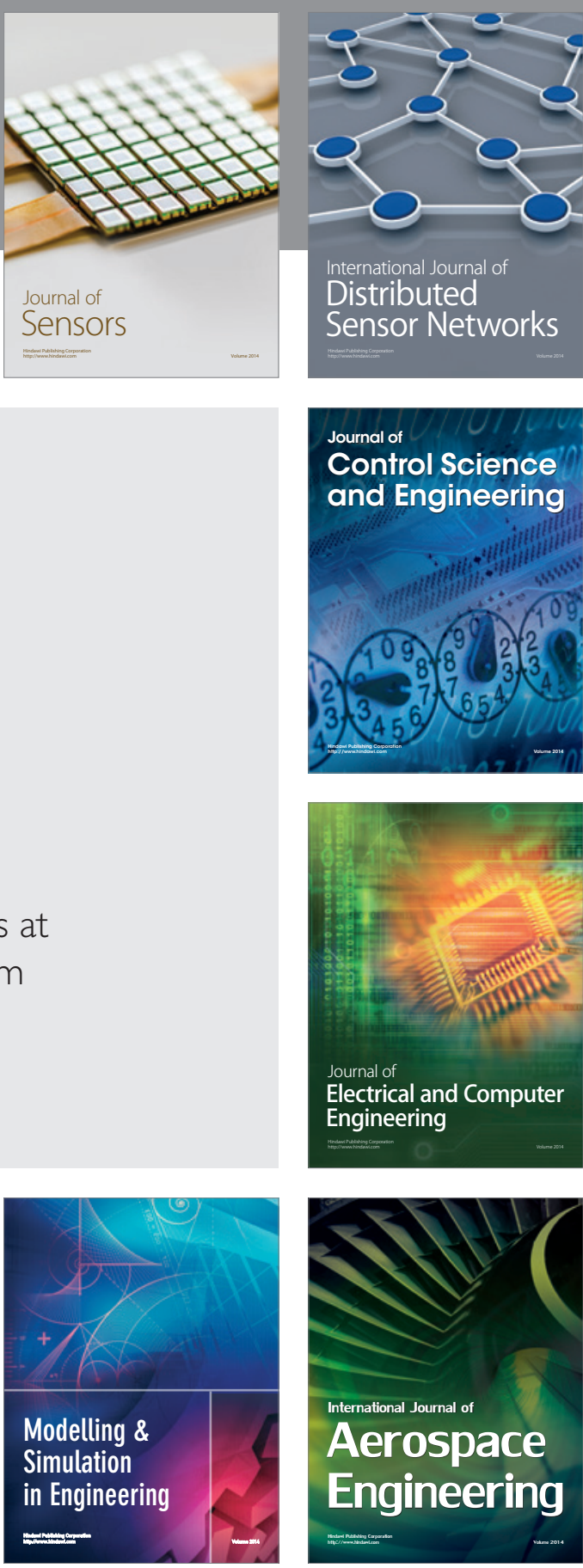

International Journal of

Distributed

Sensor Networks

Journal of

Control Science

and Engineering
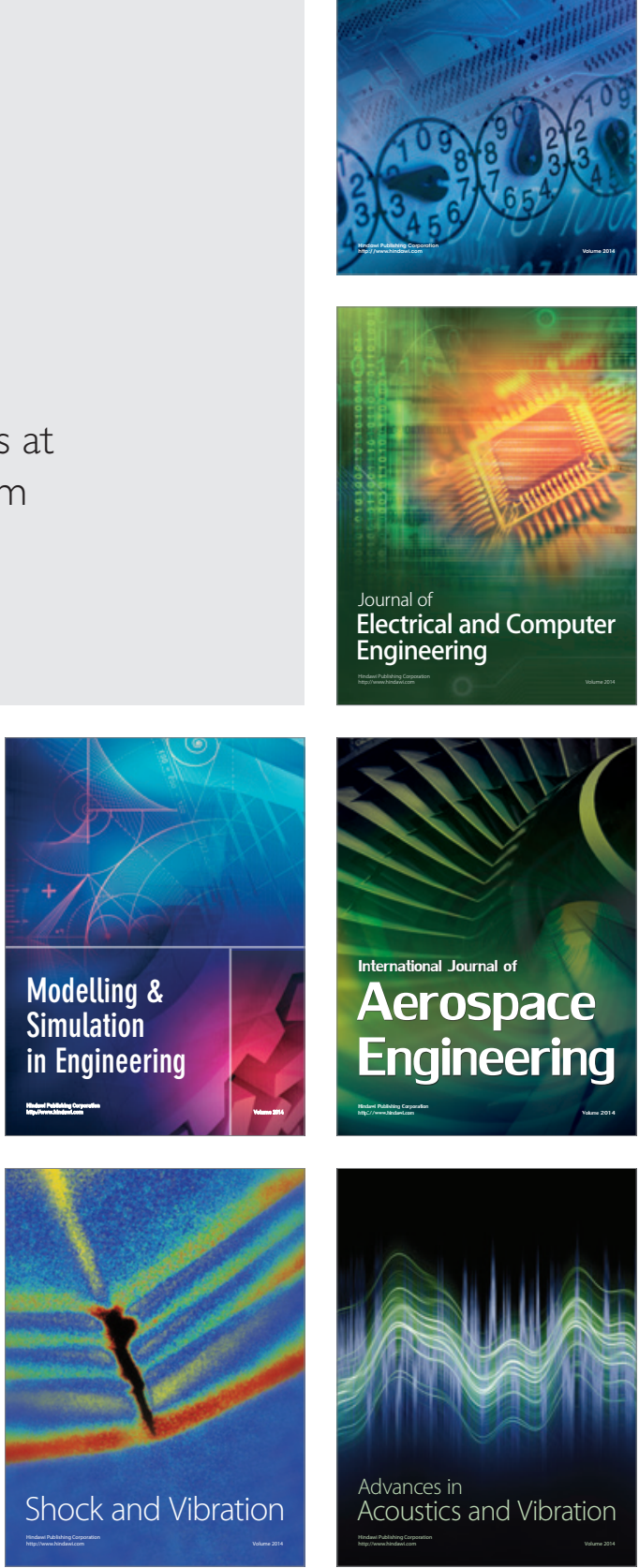